\title{
Gene-environment in the induction of cancer
}

\author{
Herman Autrup \\ From 16th International Charles Heidelberger Symposium on Cancer Research \\ Coimbra, Portugal. 26-28 September 2010
}

It has long been known that environmental factors play an important role in the induction of cancer, whereas the attributable fraction to genetic factors is less. However twin studies indicate that gene-environment interaction is of great importance. The focus is here on low penetrance genes, especially on genes involved in the biotransformation of environmental carcinogens, enzymes involved in the defense against oxidative stress, and repair of DNA damage induced by the environmental carcinogen. Early studies focused on the effect of SNPs in xenobiotica metabolizing enzymes, eg. Members of the cytochrome P450 and GST families of enzymes, but as the technology to detect genetic profiles has progressed, the studies moved from SNP to haplotypes and more recently genome wide analysis. However, most of the published studies is focused on single SNP, or combinations of SNP rather than on haplotypes. Focus of this presentation will be on breast cancer risk mostly based upon studies in the Danish part of the EPIC cohort. Only few environmental risk factors for the induction of breast cancer has been identified, e.g. alcohol consumption, cigarette smoking.

Members of the GST familie of enzymes are normally involved in the detoxification of environmental carcinogens and chemotherapeutic agents by conjugation process using reduced glutathione as a cofactor. Furthermore, they can be involved in the detoxification of reactive oxygen species. The role of several family members, GSTM1, GSTT1, GSTP1, GSTA1 and GSTO1 in breast cancer oncogenesis has been investigated in the Danish Epic cohort involving 79729 women aged 50-64 years, and born in Denmark. The design was nested-case control.

The polymorphisms in GSTM1 and T1 are deletion mutations, whereas the polymorphism in P1 is the coding sequence, and thus results in an enzyme with an altered substrate specificity. However, these polymorphism did not have an significant effect on breast cancer risk

Correspondence: ha@mil.au.dk

School of Public Health, University of Aarhus, Aarhus, Denmark neither alone or in combination with dietary intake. Similarly no association was found between GSTA1 polymorphism and breast cancer risk, whereas the GSTO1 *B/"b was associated with an increased risk, an association that was strongest in estrogen receptor positive breast cancer.

Alcohol is considered a risk factor for breast cancer, an effect that could either be mediated either by its ability to metabolic transformation to the carcinogen acetaldehyde, induction of reactive oxygen species or induction of hormone metabolizing enzymes. Alcohol dehydrogenase is involved in the oxidative formation of acetaldehyde. A genetic polymorphism in ALD1C (Arg272Gln) associated with high activity (Arg272) was found to be associated with a $14 \%$ increased risk per $10 \mathrm{~g}$ alcohol/day. Glutathione peroxidase 1 (GPX) is an antioxidant enzyme. A genetic polymorphism Pro198Leu has been detected, and a low activity was associated was linked to an increased breast risk Alcohol intake was correlated with increased alcohol intake only in carriers of the allele coding for Pro(198).

During the preparation of meat at high temperature, food mutagens are formed. Some of these compounds have shown to induced breast cancer in experimental animals. Aromatic amines are metabolized by Nacetyltransferase to acetylated products. Several polymorphisms have been detected in NAT2, and people were grouped into low and fast metabolisers. An increased risk of breast cancer was observed in people with high intake of red meat, but an interaction was only observed in the intermediate/fast acetylators.

A few studies have also addressed the role of these genetic polymorphisms on the prognosis of breast cancer. However, the data is generally inconsistent, but both GST and manganese superoxide dismutase polymorphisms has been associated with the prognosis of the disease.

Genetic polymorphisms in genes coding for xenobiotica metabolizing enzymes only play a minor role in the 
induction of breast cancer, however in the present of a well-defined exposure an interaction between gene and environmental risk occurs.

Published: 24 September 2010

doi:

Cite this article as: Autrup: Gene-environment in the induction of cancer. BMC Proceedings 2010 4(Suppl 2):O2.

Submit your next manuscript to BioMed Central and take full advantage of:

- Convenient online submission

- Thorough peer review

- No space constraints or color figure charges

- Immediate publication on acceptance

- Inclusion in PubMed, CAS, Scopus and Google Scholar

- Research which is freely available for redistribution

Submit your manuscript at www.biomedcentral.com/submit 